\title{
A (NÃO) VINCULAÇ̃̃O DOS PRECEDENTES ÀS DECISÕES PROFERIDAS EM SEDE DE ARBITRAGEM SOB A ÓTICA DO NOVO CÓDIGO DE PROCESSO CIVIL.
}

\author{
Flávio Couto Bernardes ${ }^{1}$ \\ Suélen Marine Silva ${ }^{2}$
}

\section{RESUMO}

Este trabalho tem por objeto de estudo o impacto do novo código de processo civil nas sentenças arbitrais com a instituição dos precedentes, considerando a vinculação ou não do árbitro ao proferir sua decisão. A metodologia adotada foi o estudo da legislação pátria e da doutrina sobre o tema. Por fim, conclui-se que o árbitro é vinculado à convenção de arbitragem, independentemente do modelo de procedimento arbitral a ser convencionado, podendo ser utilizado os institutos jurídicos do distinguishing ou do overruling para afastar o precedente judicial.

Palavras chaves: Arbitragem. Processo. Novo Código de Processo Civil. Sentença arbitral. Vinculação aos Precedentes.

\section{THE (NON) BINDING OF THE PRECEDENTS TO THE DECISIONS RENDERED IN ARBITRATION UNDER THE VIEWPOINT OF THE NEW CODE OF CIVIL PROCEDURE.}

\begin{abstract}
The purpose of this paper is to study the impact of the new civil procedure code on arbitration awards with the institution of precedents, considering whether or not the arbitrator is bound when making its decision. The methodology adopted was the study of the country's legislation and the doctrine on the subject. Finally, it is concluded that the arbitrator is bound to the arbitration agreement, regardless of the model of arbitration procedure to be agreed, and may be used to distinguishing or overruling legal institutions to remove the judicial precedent.
\end{abstract}

Keywords: Arbitration. Process. New Code of Civil Procedure. Arbitration award Link to the Precedents.

\section{Introdução.}

\footnotetext{
${ }^{1}$ Doutor (2006), Mestre (2000) e Bacharel (1994) em Direito pela Universidade Federal de Minas Gerais. Membro do corpo docente do Programa de Pós-Graduação em Direito da Pontifícia Universidade Católica de Minas Gerais. Professor de Direito Tributário e Financeiro da UFMG. Procurador do Município de Belo Horizonte. Secretário da Associação Brasileira de Direito Tributário - Abradt. Advogado.

E-mail: flavio.bernardes@ bernardesadvogados.adv.br

${ }^{2}$ Mestranda em Direito Público pela Pontifícia Universidade Católica de Minas Gerais. Especialista em Direito Processual (2017) e Direito de Empresa (2017) pelo Instituto de Educação Continuada da Pontifícia Universidade Católica de Minas Gerais. Bacharel em Direito pela Pontifícia Universidade Católica de Minas Gerais (2016). Advogada. E-mail: suelen_marine@yahoo.com.br
} 
O novo Código de Processo Civil de 2016 trouxe como novidade a previsão do instituto jurídico dos precedentes, típico nos sistemas jurídicos da common law, como previsto no artigo 927, $\S 5^{\circ}$. Dessa forma, o precedente, mais especificamente a ratio decidendi, passa a incorporar o ordenamento pátrio com a obrigatoriedade de sua adoção na sua aplicação jurisdicional.

O objetivo do presente artigo é investigar qual o impacto causado pela adoção dos precedentes na arbitragem, regulada pela Lei n. 9.307 de 1996, destacando-se o seguinte problema: seria a decisão arbitral vinculada ao uso dos precedentes?

Esta indagação se faz necessária considerando a importância dos precedentes na estabilidade do sistema jurídico e o fato de que a opção pela arbitragem como modelo de solução de conflitos vem aumentando nos últimos anos, sendo que o tema poderá acarretar significativa controvérsia doutrinária e até mesmo judicial quanto à obrigatoriedade de sua utilização.

Seguindo esse formato, a técnica de abordagem utilizada para esta pesquisa social aplicada e jurídica será a vertente jurídico-dogmática, com base no raciocínio dedutivo, no intuito de fundamentar a lógica e os procedimentos do Direito. Ato contínuo, a metodologia a ser utilizada consistirá na realização de pesquisa na doutrina e legislação nacional, analisando o sistema jurídico (constitucional e processual) pátrio, notadamente com relação à investigação, interpretação e avaliação das leituras bibliográficas e jurisprudenciais selecionadas.

Para o desenvolvimento do estudo será realizada breve incursão no histórico da arbitragem no país, bem como das principais inovações introduzidas pelo CPC de 2016 sobre esta matéria, como a criação da Carta Arbitral, instrumento de cooperação entre o juízo arbitral e o poder judiciário.

Sobre os precedentes será tratado os aspectos principais de sua utilização no sistema jurídico da Common Law, examinando a necessidade de sua adaptação em virtude de sua introdução no ordenamento jurídico brasileiro, considerando sua base romano-germânica. Diante do problema suscitado, buscou-se na identificação da natureza jurídica do mecanismo de solução de conflito arbitral e da finalidade dos precedentes no âmbito do sistema jurídico a conclusão quanto à vinculação dos árbitros por ocasião das decisões proferidas.

Por fim, caso a convenção arbitral opte pelo uso dos precedentes ou pela arbitragem de direito, o arbitro poderá afastar os precedentes fazendo uso das técnicas do distinguishing e 
do overruling, mas fundamentando devidamente sua sentença para não incorrer na nulidade estabelecida pelo artigo 32, inciso IV, da Lei nº 9.307 de 1996.

\section{Breves considerações sobre a arbitragem no Brasil.}

O instituto da arbitragem, forma de autocomposição entre as partes mediante a utilização do que se convencionou denominar de justiça privada, remonta a épocas antigas, tendo relatos históricos na Babilônia no Código de Hammurabi. Há registro também de sua existência na Grécia antiga.

A arbitragem na época do Império Romano, segundo o professor Rosemiro Pereira Leal (2011, p. 20-22), é dividida por períodos ${ }^{3}$, que são: período sacerdotal ou pré-romano; período da legis actiones; período formular - direito romano arcaico; período formular direito romano clássico; e período da cognitio extra ordinem - direito romano pós-clássico.

No direito romano os árbitros eram escolhidos pelas partes ou pelo pretor para resolverem os conflitos em um modelo de justiça privada, sem ou com pouca interferência do Estado, conforme o período em que se encontra.

Com a evolução do direito, o monopólio da atividade jurisdicional passou para o Estado e a arbitragem como era conhecida foi abolida. A atividade do Estado de dizer o direito denominou-se jurisdição.

Sobre a arbitragem ser um instituto antigo e ter similaridade com a arbitragem hodierna, Pedro Cavalcanti Rocha (2017), ao analisar a arbitragem na Grécia antiga, faz a seguinte conclusão: "Esse procedimento é curioso, pois apesar de antigo, se aproxima

\footnotetext{
${ }^{3}$ Segundo o professor Rosemiro Pereira Leal (2011, p. 20-22) no período sacerdotal ou pré-romano a arbitragem era o grau resolutivo da mediação, e que inicialmente espontânea e não prevista em lei, se dava pela livre escolha de terceiros (sacerdotes, pajés, anciãos) predestinados à compreensão do direito humano e divino para decidirem litígios. O período da legis actiones, século VIII ao século $\mathrm{V}$ a.C., possuía três características: judicial, legal e formalista. Foi nesse período que foi consolidada a lei das XII Tábuas. No período formular - direito romano arcaico, aboliu-se o sistema rígido das legis actiones e a função de árbitros passou a ser exercido pelos peritos. No século $\mathrm{V}$ ao II a.C, ao lado de uma mediação facultativa, criou-se uma arbitragem oficial, de modo híbrido, pelo magistrado (pretorservidor público) e pelo juiz (árbitro particular), advindo a prevalência pública. No período formular direito romano clássico, século II a.C. ao século III a.C., marcou o encerramento do que se chama ciclo da justiça privada ou período formular, no qual a arbitragem já assume feições de instituto jurídico público e cogente com impositividade governamental na escolha do juiz de fato (árbitro) pelo pretor. Por fim, o período da cognitio extra ordinem - direito romano pós-clássico assinala a passagem do modelo romano da justiça privada para a justiça pública. O monopólio da atividade de dizer o direito, abolindo oficialmente a arbitragem facultativa, era o pretor o órgão jurisdicional do Estado e o Estado o único e exclusivo árbitro dos litígios. A essa atividade denominou-se jurisdição.
} 
bastante com a nova sistemática do procedimento ordinário do novo Código de Processo Civil".

Estas breves considerações históricas são apontadas para demonstrar a origem do instituto jurídico da arbitragem, demonstrando que se trata de mecanismo milenar de solução de conflitos que voltou a ser discutido a partir do reconhecimento de que a jurisdição não precisar ser necessariamente estatal, sem que isso macule a teoria da separação dos poderes.

Pedro Martins (2010) afirma que a arbitragem tem singular tradição no Brasil, apesar de sua jovialidade no ordenamento juridico. Isto porque, questões fronteiriças com a Argentina e a Guiana Britânica foram resolvidas por meio de arbitragem em 1900 e 1904 respectivamente; a disputa do território do Acre com a Bolívia também se resolveu pelo sistema arbitral; o naufrágio do navio Canadá norte americano na costa brasileira foi resolvido pela arbitragem em 1870; por fim, a questão Christie $^{4}$, ocorrida em 1863, também foi resolvida por arbitragem na época do Império.

Há que se ressaltar também que o Barão de Itajubá compôs painel arbitral internacional, tendo participado do julgamento dos conflitos ocorridos na guerra de Secessão dos Estados Unidos - caso Alabama em $1872^{5}$.

Já no Direito Privado, a Constituição do Império de 1824, no artigo 160, previa o uso da arbitragem para a solução de disputas entre brasileiros e estrangeiros. E a arbitragem foi introduzida em 1831 e 1837 nas leis de contrato de seguro e de locação de serviço, respectivamente, como meio de solução de litígios.

O Código Comercial de 1850 institui a arbitragem como meio de resolução de conflitos de questões societárias, contratuais e de falência. O Código Civil de 1916 e os Códigos de Processo Civil de 1939 e 1973 também reservaram espaço para tratar da

\footnotetext{
${ }^{4}$ A Questão Christie foi um evento conflituoso, na área de relações diplomáticas, entre Brasil e o Reino Unido. Ocorreu durante o Segundo Reinado, no ano de 1863, resultando na quebra das relações diplomáticas entre as duas nações. As relações foram restauradas somente em 1865. Disponível in: < https://www.historiadobrasil.net/brasil_monarquia/questao_christie.htm>. Acesso em 15 jul. 2018.

${ }^{5}$ Arbitragem entre os Estados Unidos e o Reino Unido, relacionada à Guerra Civil Americana, ocorrida entre 1861 e 1865. Os EUA reclamavam o pagamento de danos ao governo do Reino Unido pelo apoio dado às forças Confederadas durante a guerra. A arbitragem internacional deu ganho de causa aos EUA, o que determinou o pagamento de US\$ 15 milhões pelo governo inglês como indenização pelos estragos causados pelos navios construídos pelos ingleses e vendidos aos Confederados. A arbitragem colocou fim à disputa e garantiu as relações amigáveis entre os dois países. Disponível in: < https://pgderolle.wordpress.com/2015/04/06/os-principais-casos-de-direitointernacional-publico-para-o-cacd/>.
} 
arbitragem. O atual Código de Processo Civil de 2015 também traz inovações para a matéria da Arbitragem, como será examinado adiante.

Petrônio Gonçalves Muniz, em 1991, liderou grupo de pesquisa denominado Operação Árbiter, desenvolvendo uma proposta de criação de uma Lei de Arbitragem que foi debatida no Seminário Nacional de Arbitragem em 1992. Neste mesmo ano, o senador Marco Maciel apresentou o anteprojeto da Lei de Arbitragem na Câmara dos Deputados, organizado por Carlos Alberto Carmona, Selma M. Ferreira Lemes e Pedro A. Batista Martins, que mais tarde culminou na Lei $\mathrm{n}^{\circ}$ 9.307, de 1996.

Essa a legislação incorpora no ordenamento jurídico pátrio as regras que passam a disciplinar a arbitragem, tendo sua constitucionalidade ${ }^{6}$ arguida em 2001 devido ao conteúdo do inciso XXXV do artigo $5^{\mathrm{a}}$ da Constituição da República, que prevê que "a lei não poderá excluir da apreciação do Poder Judiciário lesão ou ameaça a direito".

No julgamento em referência sete ministros do Supremo Tribunal Federal entenderam que o dispositivo constitucional se dirige às autoridades legislativas objetivando proteger o cidadão de abuso ou ato arbitrário cometido pelo Executivo ou Legislativo, reconhecendo a liberdade do cidadão de escolher se renuncia ao direito, transaciona ou resolve o conflito no judiciário ou pela via arbitral. Os outros quatro ministros entenderam pela inconstitucionalidade da arbitragem como sistema definitivo na resolução de litígios.

Na obra Teoria Geral do Processo, CINTRA, GRINOVER e DINAMARCO (2006, p. 36-37) fazem a delineação do juízo arbitral no direito brasileiro, in verbis:

O juízo arbitral é delineado no direito brasileiro da seguinte forma: a) convenção de arbitragem (compromisso entre as partes ou cláusula compromissória inserida em contrato: lei cit., art. $3^{\circ}$ ); b) limitação aos litígios relativos a direitos patrimoniais disponíveis $\left(\operatorname{art.~} 1^{\circ}\right.$ ); c) restrições à eficácia da cláusula compromissória inserida em contratos de adesão (art. $4^{\circ}, \S 2^{\circ}$ ); d) capacidade das partes $\left(\operatorname{art.} 1^{\circ}\right.$ ); e) possibilidade de escolherem as partes as regras de direito material a serem aplicadas na arbitragem, sendo ainda admitido convencionar que esta "se realize com base nos princípios gerais de direito, nos usos e costumes e nas regras internacionais de comércio" (art. $2^{\circ} \S \S 2^{\circ}$ e $3^{\circ}$ ); f) desnecessidade de homologação da sentença arbitral (art. 31); g) atribuição a esta dos mesmos efeitos, entre as partes, dos julgados proferidos pelo Poder Judiciário (valendo inclusive como título executivo, se for condenatória: art. 31); h) possibilidade de controle jurisdicional ulterior, a ser provocado pela parte interessada (art. 33, caput e $\S$ ); i) possibilidade de reconhecimento e execução de sentença arbitrais produzidas no exterior (arts. 34 ss.). Mas os árbitros, não sendo investidos do poder jurisdicional estatal, não podem

\footnotetext{
${ }^{6}$ Recurso SE 5206, Relator: Ministro SEPÚLVEDA PERTENCE, Tribunal Pleno, Julgado em $12 / 12 / 2001$.
} 
realizar a execução de suas próprias sentenças nem impor medidas coercitivas (art. $\left.22, \S 4^{\circ}\right)$.

Tendo em vista a delineação da arbitragem no direito brasileiro e levando em conta o direito disponível, a celeridade, sigilo e especialidade dos árbitros escolhidos pelas partes para resolver o conflito, a arbitragem tem sido considerada a via que poderá trazer resultados mais rápidos e satisfatórios às partes. Conforme elucida Arnoldo Wald (2007), “o processo judicial está cada vez mais inadequado para fornecer soluções em tempo útil" e como a sociedade tem cada vez mais pressa para a solução de seus conflitos e negociações, a arbitragem é a melhor via a ser adotada.

Verifica-se, assim, que a arbitragem é instituto que remonta às origens do direito como é conhecido hodiernamente, sendo que o Brasil possui tradição na arbitragem desde a época imperial. O reconhecimento da constitucionalidade da jurisdição arbitral possibilitou seu desenvolvimento acelerado no direito pátrio, permitindo que o novo modelo de solução de conflitos, nos limites definidos para sua utilização, contribuísse de forma decisiva para o aprimoramento dos litígios que envolvam grandes negócios empresariais.

\subsection{Mudanças na arbitragem com o novo código de processo civil.}

Atualmente o Brasil está entre as maiores economias do globo. Como consequência, o fluxo de negócios e investimentos aumentou consideravelmente nos últimos anos. Este crescimento econômico e a internacionalização nas relações jurídicas entre empresas nacionais e estrangeiras demandou o rápido aumento da utilização da arbitragem e no consequente surgimento de Câmaras especializadas. Neste sentido, Bruno Guimarães Bianchi (2016) traz a seguinte informação:

Prova disso é o fato de que, apenas no ano de 2014, mais de 310 procedimentos arbitrais foram instituídos em território nacional. Menos da metade do número de novos procedimentos arbitrais da Câmara de Comércio Internacional no mesmo período - 791 novos procedimentos naquela corte - mas é um número relevante, diante do fato de que em 2008 tivemos 170 procedimentos arbitrais iniciados em território brasileiro.

Diante da informação citada, insta ressaltar que a legislação de arbitragem pátria é considerada um avanço e em 2015 sofreu modificação por meio da Lei 13.129 de 2015 para ampliar a arbitragem para a administração pública. 
Esta consolidação no uso da jurisdição arbitral também foi contemplada na reformulação da legislação processual brasileira, sendo que o Código de Processo Civil recentemente promulgado contempla este instituto em mais de 15 dispositivos. No parágrafo $1^{\circ}$ do artigo $3^{\circ}$ o legislador deixou expresso que a arbitragem constitui mecanismo de apreciação jurisdicional de qualquer ameaça ou lesão a direito, tratando-se da materialização constitucional dos princípios processuais retores da legislação processual pátrio. No artigo 42, ao estipular que "As causas cíveis serão processadas e decididas pelo juiz nos limites de sua competência, ressalvado às partes o direito de instituir juízo arbitral, na forma da lei”, deixa expressa a competência estatal e a competência arbitral.

No entanto, ainda permanece a restrição quanto ao poder coercitivo da arbitragem, sendo que a execução de sua decisão deve ser submetida ao poder judiciário não para reapreciar a matéria, para como única jurisdição que por enquanto mantém o poder de adotar os mecanismos necessários ao cumprimento da decisão judicial ou arbitral. Para tanto, a parte interessada deve ajuizar nova demanda para dar cumprimento à sentença arbitral, nos termos do inciso III do artigo 516 do novo CPC.

Outro ponto importante é a questão da confidencialidade. O artigo 189, inciso IV, deixa expresso que se houver confidencialidade estipulada na arbitragem e comprovada perante o juízo, o cumprimento de sentença e qualquer demanda que envolva arbitragem no judiciário correrão de forma confidencial.

Todavia, o novo código de Processo Civil falhou ao vetar a exceção de arbitragem, pois o artigo 337 estipula que a incompetência do juízo estatal decorrente da cláusula arbitral deverá ser arguida e em sede de preliminar de contestação. Se acolhida o processo será extinto com fulcro no artigo 485, inciso VII, do novo CPC, apesar de já exposta a estratégia de defesa que será replicada na jurisdição arbitral.

Por fim, a novidade trazida pelo novo CPC foi a criação do instituto chamado Carta Arbitral, instituída no artigo 237, inciso IV, que estabelece:

Art. 237 - Será expedida carta:

$[\ldots]$

IV - arbitral, para que órgão do Poder Judiciário pratique ou determine o cumprimento, na área de sua competência territorial, de ato objeto de pedido de cooperação judiciária formulado por juízo arbitral, inclusive os que importem efetivação de tutela provisória. 
A Carta Arbitral se assemelha com as cartas precatórias, rogatórias e de ordem. É o instrumento de cooperação entre a jurisdição estatal e o juízo arbitral. Mecanismo pelo qual o o árbitro pode solicitar ao juiz competente, após a distribuição, que seja usado a força coercitiva para o cumprimento de alguma ordem pelo juízo arbitral, como, por exemplo, condução coercitiva de testemunhas e forçar a parte contrária a cumprir determinada decisão proferida pelo árbitro.

Conclui-se que o novo Código de Processo Civil trouxe mudanças significativas para a arbitragem, consolidando sua utilização como parte da jurisdição brasileira para a solução dos litígios, incorporando o que fora reconhecido na análise da constitucionalidade pelo Supremo Tribunal Federal. Exatamente neste cenário que se torna imprescindível ingressar na discussão proposta, ou seja, se o instituto jurídico dos precedentes também deve ser observado na arbitragem, passando pelo destaque da função da jurisprudência no sistema jurídico.

\section{Função da jurisprudência no sistema jurídico}

A função constitucional da jusprisprudência é harmonizar e uniformizar as decisões judiciais de modo a conferir coerência e estabilidade ao sistema jurídico. Nesse aspecto, a força normativa desagua para a garantia da segurança jurídica, circunscrevendo o âmbito de interpretação normativa dos aplicadores e, ao mesmo tempo, evitando a produção de decisões teratológicas. O enquadramento legal evita a dissonância semântica da aplicação e, para além disso, a utilização do poder jurisdicional de forma conveniente e antagônica quanto a seu agir ${ }^{7}$

Surge, dessa maneira, a necessidade de lembrar que no regime do sistema civil law adotado no direito brasileiro, a jurisprudência possui o papel de uniformização da inteligência dos enunciados das decisões que formam o ordenamento jurídico. Essa função jurisprudencial é, aliás, uma das formas do direito processual prestigiar, acima de tudo, a segurança jurídica.

\footnotetext{
7 "Entre os dois tipos ideais de uma jurisprudência vinculada a leis estaduais e de uma jurisprudência liberta das leis estaduais, situam-se aqueles sistemas nos quais, sendo embora instituído um órgão legislativo central, os tribunais recebem o poder não só de fixar normas jurídicas individuais nos quadros das normas gerais criadas pelo órgão legislativo mas também - em circunstâncias determinadas, já acima referidas - de fixar normas individuais fora destes quadros; e, por fim, aquele sistema em que os tribunais têm poder de criar normas jurídicas gerais sob a forma de decisões com força de precedentes. Estes diferentes sistemas representam diferentes graus de centralização ou descentralização da função produtora do Direito e, portanto, diferentes graus de realização do princípio da flexibilidade do Direito, que está na razão inversa do princípio da segurança jurídica." (KELSEN, 1998, p. 177).
} 
O novo Código de Processo Civil (CPC/2015) procurou, com isso, garantir uma coerência nas decisões jurídicas e efetividade aos princípios constitucionais, como o da segurança jurídica. Em seu artigo 927, parágrafo $4^{\circ}$, o novo CPC reproduziu expressamente este entendimento ao ressaltar que a modificação de jurisprudência consolidada observará a necessidade de fundamentação adequada e específica, considerando os princípios da segurança jurídica, da proteção da confiança e da isonomia. ${ }^{8}$

Todavia, de nada adianta o CPC ter dedicado tratamento especial à jurisprudência se não houver uniformidade e coerência entre elas. Via de regra, as decisões jurídicas deveriam procurar a ratio decidendi sobre a qual outros julgados se basearam para realizar uma interpretação adequada e garantir a coerência (e confiança) nas sentenças.

Sem previsibilidade não há coerência; e sem coerência não há segurança jurídica. A unidade da ciência jurídica e a eficácia do ordenamento somente ocorrem pela integração e coordenação de suas normas (BERNARDES, 2006, p. 161-162).

Nesse aspecto que deve ser ressaltado a função da jurisdição no ordenamento jurídico, pois é exatamente através da sua atuação que se consolida a aplicação das normas jurídicas vigentes quanto à interpretação que venha a ser considerada como válida pelo sistema, possibilitando todos estes ideais que resguardam na segurança jurídica que deve ser inerente ao próprio sistema.

Dessa forma, necessário a análise do instituto dos precedentes como corolário da aplicação correta da norma no sistema jurídico, realizada em caráter definitivo tanto pela jurisdição pública como pela privada, para analisar se sua utilização vincula apenas e tão somente o poder judiciário ou também aos árbitros integrantes do modelo arbitral.

\section{Precedentes no novo código de processo civil.}

A Constituição da República prevê o sistema dos precedentes no ordenamento jurídico pátrio nos artigos 102, inciso I, alínea “l”; 103-A, §3; 105, inciso I, alínea “f”; e 111$\mathrm{A}, \S 3^{\circ}$, garantindo o direito à reclamação constitucional para garantir que as decisões dos tribunais sejam cumpridas, a fim de gerar a estabilidade e segurança jurídica no sistema.

\footnotetext{
8 “Art. 927. [...] "§ $4^{\circ}$ A modificação de enunciado de súmula, de jurisprudência pacificada ou de tese adotada em julgamento de casos repetitivos observará a necessidade de fundamentação adequada e específica, considerando os princípios da segurança jurídica, da proteção da confiança e da isonomia." (BRASIL, CPC, 2015).
} 
Nessa seara, o CPC de 2015 inclui o instituto jurídico do precedente no artigo 927, $\S 5^{\circ}$, que tem sua origem na Common Law, mais precisamente na Inglaterra. Sobre a conceituação do precedente, Fredie Didier Jr e outros (2016, p. 455) asseveram:

\begin{abstract}
Em sentido lato, o precedente é a decisão judicial tomada à luz de um caso concreto, cujo elemento normativo pode servir como diretriz para o julgamento posterior de casos análogos.

$\mathrm{O}$ precedente é composto pelas: a) circunstâncias de fato que embasam a controvérsia; b) tese ou princípio jurídico assentado na motivação (ratio decidendi) do provimento decisório; c) argumentação jurídica em torno da questão.

Assim, embora comumente se faça referência à eficácia obrigatória ou persuasiva do precedente, deve-se entender que o que pode ter caráter obrigatório ou persuasivo é a sua ratio dcidendi, que é apenas um dos elementos que compõem o precedente.
\end{abstract}

A Common Law surgiu na Inglaterra no século XI, base de um sistema jurídico vinculado precipuamente ao direito consuetudinário, conferindo aos órgãos julgadores, portanto, parte essencial na formação e fechamento do próprio sistema, já que em última instância é a jurisdição que define o direito aplicável. Exatamente a definição dos casos paradigmáticos pelos órgãos jurisdicionais que permite a criação do precedente como mecanismo principal para conferir a estabilidade e o fechamento no sistema jurídico, permitindo que os casos nele enquadráveis tenham o mesmo resultado, isto é, que se possibilite a coesão e a estabilidade que propiciam a segurança jurídica no sistema.

No direito brasileiro, que adota sistema diverso, a estabilidade e a coerência que garantem a premissa da segurança jurídica são lastreadas na norma jurídica validamente posta no ordenamento. Todavia, a crescente divergência no uso da interpretação propalou o uso desenfreado das diversas teorias da argumentação, acarretando uma abertura no sistema que naturalmente ocasionou sua instabilidade. Nesse contexto que a incorporação da figura jurídica dos precedentes busca, sem prescindir obviamente da interpretação e seus métodos, assegurar que a jurisdição seja coerente na orientação baseada nas suas próprias decisões.

$\mathrm{Na}$ tradição brasileira, a intitulada jurisprudência dominante buscava assegurar esta coerência nas decisões proferidas pelo poder judiciário em relação aos demais casos que se baseavam na mesma ratio decidendi. No entanto, esta premissa começou a não ser mais considerada por diversos motivos que fogem ao escopo do presente trabalho, mas que passou a resultar em decisões conflitantes da mesma fonte prolatora na análise dos casos concretos. Ainda com o intuito de evitar esta ruptura inaceitável no sistema, foram criadas súmulas e 
decisões em controle concentrado de constitucionalidade com efeito vinculante aos órgãos julgadores, que teriam a mesma finalidade dos precedentes. Ainda assim não se mostrou suficiente, o que levou a comissão de autores do anteprojeto do Código de Processo Civil e, posteriormente, o legislador, a incorporar no ordenamento pátrio o instituto dos precedentes.

A crítica que alguns juristas fazem sobre o uso do precedente no Brasil, que diferente da jurisprudência dominante tem força vinculante, é justamente colocar um fim no debate sobre os temas e não voltar mais neles, engessando assim o direito brasileiro.

Pois bem, uma das principais críticas a tecer sobre a instituição do precedente pelo novo CPC é a ausência de diálogo entre os membros dos órgãos judiciário, ou seja, deve haver deliberação, o que não ocorre nos nossos tribunais.

Deliberação é o diálogo entre os juízes que compõe os tribunais no qual eles devem superar os argumentos propostos por cada um com a finalidade de obter uma decisão única da corte. Tal fato não ocorre nos tribunais do Brasil, como esclarece o professor Júlio Aguiar (2016, p. 147) ao afirmar que no STF não há deliberação, sendo assim, não há uma decisão da corte, mas sim onze decisões de cada dos ministros. Diz o referido professor:

O STF decide por agregação de opiniões e não elabora uma fundamentação unificada de sua argumentação. Cada voto traz uma decisão e os argumentos que a fundamentam, mas a decisão final, a decisão da corte, não explicita sobre quais fundamentos se sustenta. Em sentido estrito, há onze opiniões, mas não há uma opinião do tribunal.

(Omissis)

A desorganização da apresentação das decisões do STF, como Rodrigues registra com acerto, não é expressão de um acidente. As decisões não são organizadas de maneira unificada, de modo a explicitarem as razões que as fundamentam, porque isso, dada a forma mesma de decidir do STF, é impossível. A corte, como se verá mais à frente com mais detalhes, não delibera. Sem deliberação, consequentemente, não há como reconhecer e explicitar as razões da decisão.

Os precedentes podem sim ser adotados, mas para isso deverá haver uma reforma na forma como as sessões de julgamentos são feitas. A deliberação deverá ser instituída entre os membros dos tribunais e só assim poderá haver formação de precedentes que não engessem o direito brasileiro e tampouco coloque fim a discussão.

\section{A instauração do procedimento arbitral.}


A arbitragem é composta por três fases: a pré arbitral, a fase arbitral e pós arbitral. A Lei $\mathrm{n}^{\circ} 9.307$ de 1996 estabelece no artigo $1^{\circ}$ que "As pessoas capazes de contratar poderão valer-se da arbitragem para dirimir litígios relativos a direitos patrimoniais disponíveis".

Logo, a arbitragem é expressão máxima da autonomia da vontade das partes, que escolhem os árbitros que irão julgar a lide, sempre em número ímpar, conforme estabelecido na lei, definem as regras de direito interno ou externo e os princípios a serem aplicados na causa.

Ao elaborar um contrato que envolva direitos patrimoniais e disponíveis, as partes podem optar pela arbitragem (fase pré-arbitral). Essa opção se dá por meio da cláusula compromissória que deverá ser preferencialmente cheia (contendo todos os termos da arbitragem como nomeação e honorários dos árbitros, local da arbitragem, regras a serem adotadas, etc.)

Instaurado o conflito, as partes assinam o compromisso arbitral que deverá constar os requisitos essenciais do artigo 10 e ainda poderá conter os elementos do artigo 11 da lei de regência. Cumpre ressaltar que a cláusula arbitral e o compromisso arbitral são tratados pela lei como convenção de arbitragem. Caso a cláusula compromissória já contenha todas as regras de como se dará a arbitragem, o compromisso arbitral será assinado por mera formalidade.

A arbitragem só tem início quando os árbitros aceitam a nomeação nos termos do artigo 19 da Lei $\mathrm{n}^{\circ} 9.307$ de 1996 e as partes deverão assinar o termo de arbitragem, dando início a fase arbitral. Os árbitros iniciarão os trabalhos de acordo com as regras e local escolhidos pelas partes.

As partes apresentarão suas razões iniciais com todos os seus pedidos a respeito do objeto da lide, as testemunhas serão ouvidas, os peritos poderão ser chamados para realizar laudos técnicos e ao fim da fase instrutória o árbitro proferirá a sentença arbitral.

Finalizando o procedimento adotado na convenção arbitral, será proferida a sentença, iniciando-se a fase pós-arbitral. Como dito, o árbitro não possui poder de coerção para poder determinar o cumprimento da sentença.

Diante do exposto, indaga-se: tendo as partes escolhido as regras a serem aplicadas na arbitragem, e entre essas regras, definido o procedimento adotado e a legislação de regência, deve o árbitro ficar vinculado aos precedentes formados a partir de decisões proferidas em outra jurisdição, neste caso a estatal? 


\section{A (não) vinculação dos precedentes à Arbitragem.}

A escolha das partes pela arbitragem é a máxima da autonomia da vontade. Quando optam pela arbitragem, as partes afastam do poder judiciário a resolução da lide, mas não a jurisdição, e na convenção de arbitragem escolhem quais as leis, princípios, regras que irão utilizar e se a arbitragem será de direito, ad hoc, institucional ou por equidade.

Antes de prosseguir, necessário elucidar os termos convenção de arbitragem em cada modalidade. Importante levar em consideração esses termos, haja vista que a convenção de arbitragem vincula o árbitro e as partes, e o tipo de arbitragem escolhida influencia no uso das regras quando o árbitro prolatar a sentença.

A convenção de arbitragem é prevista no artigo $3^{\circ}$ da Lei $n^{\circ} 9.307$ de 1996 , onde se estipula que as partes escolherão a solução do litígio por meio desse gênero de negócio jurídico, do qual são espécies a cláusula e o compromisso arbitral. Vale lembrar que é no compromisso arbitral que será entabulada as regras da arbitragem.

No tocante aos tipos de arbitragem, será arbitragem de direito aquela em que os árbitros decidirão a lide com fulcro nas regras do direito brasileiro, observando estritamente o princípio da legalidade. Ou seja, ao usar as regras de direito, os precedentes que são fontes de direito integrando as regras do direito brasileiro, também deverão ser considerados ao decidir o litígio.

A arbitragem será institucional quando seguir as regras estipuladas por uma Câmara de Arbitragem, sendo que essas regras não podem violar a legislação vigente. Será arbitragem ad hoc quando todas as regras forem escolhidas pelas partes, regras como prazo, manifestação, regras próprias para o procedimento. Ao escolher, por exemplo, a aplicação CPC na lide, as partes não poderão esquivar da aplicação dos precedentes, pois esse instituto integra o sistema jurídico

Por fim, a arbitragem por equidade é aquela em que o árbitro decide a controvérsia fora das regras de direito de acordo com seu real saber e entender. Poderá reduzir os efeitos da lei e decidir de acordo com seu critério de justo. Para que o árbitro possa decidir por equidade as partes devem prévia e expressamente autorizá-lo.

Com a promulgação do novo CPC os precedentes instituídos pelo artigo $927, \S 5^{\circ}$ passaram a ser fonte de direito. Ou seja, se na convenção de arbitragem ad hoc as partes 
optarem por utilizar o código processual civil brasileiro, o árbitro terá de utilizar os precedentes em sua decisão. Mesmo que na convenção de arbitragem ad hoc, a qual o árbitro se vincula, as partes estipulam apenas o modo pelo qual será realizado o procedimento da arbitragem, o CPC é aplicado de maneira subsidiária à lei de arbitragem, ou seja, os precedentes vinculam o arbitro ao proferir sentença.

Quando se trata de arbitragem de direito, há autores que entendem que há a vinculação dos precedentes judiciais à arbitragem, por eles serem fonte de direito. Nesse sentido argumenta Guilherme Rizzo Amaral (2017):

O árbitro vincula-se aos precedentes judiciais na medida em que as partes elegem arbitragem de direito e que os precedentes judiciais vinculantes integram o Direito brasileiro. É dizer: não está o árbitro vinculado aos precedentes por conta da (inexistente) aplicação direta de dispositivos do CPC à arbitragem, mas pela vontade das partes que deram ao árbitro a missão de julgar conforme o direito.

O entendimento prossegue no sentido de afirmar que a sentença arbitral deve seguir os requisitos instituídos pelo artigo $489, \S 1^{\circ}$, inciso $\mathrm{V}$ do novo $\mathrm{CPC}$, in verbis:

\footnotetext{
Art. 489 - São elementos essenciais da sentença: [....]

$\S 1^{\circ}$ - Não se considera fundamentada qualquer decisão judicial, seja ela interlocutória, sentença ou acórdão, que: [...]

$\mathrm{V}$ - se limitar a invocar precedente ou enunciado de súmula, sem identificar seus fundamentos determinantes nem demonstrar que o caso sob julgamento se ajusta àqueles fundamentos;
}

O professor José Rogério Tucci e Cruz (2016) entende que caso as partes escolham pelo uso do CPC e o árbitro não o use os precedentes ao prolatar a sentença, esta poderá ser anulada no judiciário com base nos requisitos do artigo 489 do novo CPC.

Entretanto a lei de arbitragem é clara ao definir os elementos da sentença no artigo 26 da lei n. 9.3017 de 1996:

Art. 26 - São requisitos obrigatórios da sentença arbitral:

I - o relatório, que conterá os nomes das partes e um resumo do litígio;

II - os fundamentos da decisão, onde serão analisadas as questões de fato e de direito, mencionando-se, expressamente, se os árbitros julgaram por eqüidade;

III - o dispositivo, em que os árbitros resolverão as questões que lhes forem submetidas e estabelecerão o prazo para o cumprimento da decisão, se for o caso; e IV - a data e o lugar em que foi proferida.

Parágrafo único. A sentença arbitral será assinada pelo árbitro ou por todos os árbitros. Caberá ao presidente do tribunal arbitral, na hipótese de um ou alguns dos árbitros não poder ou não querer assinar a sentença, certificar tal fato. 
E sobre as nulidades da sentença, prevê o artigo 32 da Lei de Arbitragem:

Art. 32 - É nula a sentença arbitral se:

I - for nula a convenção de arbitragem;

II - emanou de quem não podia ser árbitro;

III - não contiver os requisitos do art. 26 desta Lei;

IV - for proferida fora dos limites da convenção de arbitragem;

V - (Revogado pela Lei $\mathrm{n}^{\circ} 13.129$, de 2015)

VI - comprovado que foi proferida por prevaricação, concussão ou corrupção passiva;

VII - proferida fora do prazo, respeitado o disposto no art. 12, inciso III, desta Lei; e

VIII - forem desrespeitados os princípios de que trata o art. $21, \S 2^{\circ}$, desta Lei.

Invocar o novo CPC para dizer que o a decisão arbitral deve vincular aos requisitos do artigo 489 é fundamental para a estabilidade e segurança do sistema jurídico, visto que, como se verifica nos artigos 26 e 32 da Lei no 9.307 de 1996, há expressa disposição no sentido de que a sentença arbitral será nula se for proferida fora dos limites da convenção de arbitragem.

Seguindo esse raciocínio, no tocante ao uso dos precedentes judiciais, a decisão arbitral somente será passível de nulidade se for decidida fora dos limites da convenção arbitral. Conforme já mencionado, o árbitro se vincula aos precedentes para prolatar sentença, pois se encontra adstrito à convenção de arbitragem que contém as regras e a legislação que serão utilizadas na arbitragem. Se a convenção de arbitragem nada falar sobre o uso do CPC, o árbitro terá que observar os precedentes, pois é parte da jurisdição.

Ademais, mesmo que as partes optem pelo uso do código de processo civil na convenção arbitral, o árbitro poderá utilizar os mecanismos do distinguishing (distinção) e overrulling (superação) para afastar os precedentes. Nesse sentido, entendem ROQUE e GAJARDONI (2016):

Por outro lado, assim como o juiz togado, pode o árbitro lançar mão das técnicas de superação de precedentes (distinguishing ou distinção /overrulingou superação) para afastar sua incidência, destacando a inadequação ao caso concreto ou a superação do julgado paradigma, mediante fundamentação específica e qualificada.

Conforme a crítica feita ao precedente, devido ao fato de não haver deliberação nos tribunais brasileiros, e o precedente poder engessar o direito pátrio, nada mais justo do que o árbitro distinguir sua decisão do precedente invocado ou superá-lo, sem incorrer em nulidade. 
A jurisdição é una, não havendo distinção entre jurisdição estatal e privada. A arbitragem apenas afasta o judiciário na resolução da lide, mas por integrar o sistema jurídico deve se ater à legislação. No caso da arbitragem de direito o árbitro vincula a todo o sistema, incluindo os precedentes. Na arbitragem institucional, se a Câmara escolhida utilizar o CPC o árbitro está vinculado aos precedentes, e na arbitragem ad hoc apenas se as partes optarem pela aplicação da legislação processual brasileira o árbitro estará vinculado aos precedentes ao proferir sentença arbitral.

Assim, conclui-se que a decisão arbitral vincula ao uso dos precedentes instituídos pelo artigo $927 \S 5^{\circ}$ do novo CPC caso as partes, no gozo da autonomia da vontade, optem pelo uso da legislação brasileira. Importante ressaltar que o árbitro poderá utilizar as técnicas do distinguishing e do overrruling para afastar o uso dos precedentes, mas sempre os mencionando na decisão para não incorrer em nulidade do artigo 32, IV da lei no 9.307 de 1996.

\section{Conclusão.}

Conforme já mencionado, o Brasil possui tradição com o uso da arbitragem desde a época do império, já que era prevista na Constituição de 1824 no artigo 160, mas a lei sobre o tema apenas foi promulgada em 1996 sob o ${ }^{\circ} 9.307$.

Após a promulgação do novo Código de Processo Civil questionou-se qual o impacto que este teria sob a arbitragem. Conforme demonstrado ao longo do presente trabalho, restou claro que o principal impacto foi a criação da Carta Arbitral, que regulariza a cooperação entre o judiciário e o juízo arbitral.

Entretanto o novo Código de Processo Civil trouxe a novidade dos precedentes, instituídos no artigo $927 \S 5^{\circ}$, que agora são fontes de direito. Sendo os precedentes fonte de direito, são as decisões arbitrais vinculados a eles? Ao analisar o artigo 489 do novo CPC que versa sobre os fundamentos da sentença e os artigos 26 e 32 da Lei no 9.307 de 1996 que versam respectivamente sobre os requisitos e as causas da nulidade da sentença arbitral, entende-se que o argumento de que a sentença arbitral deve se submeter subsidiariamente ao $\mathrm{CPC}$ é em respeito à jurisdição e ao sistema jurídico

Os precedentes, previsto na Constituição, possuem a finalidade de estabilizar o direito e trazer segurança jurídica. Ademais, independentemente do modelo de procedimento 
arbitral escolhido, se as partes optarem por utilizar o CPC na convenção de arbitragem, o arbitro estará vinculado aos precedentes ao prolatar sentença.

Por fim, a leitura do artigo 32, IV da Lei n 9.307 de 1996 deixa claro que a sentença será nula se for decidida fora dos limites da convenção de arbitragem. Conforme exarado, o árbitro e as partes se vinculam à convenção de arbitragem.

Conclui-se que caso a convenção de arbitragem opte pelo uso da legislação brasileira, o árbitro deverá mencionar os precedentes, se houver, em sua decisão, podendo utilizá-los ou afastá-los por meio do uso das técnicas do distinguishing ou overrruling, devidamente fundamento para não incorrer em nulidade.

\section{Bibliografia.}

AMARAL, Gilherme Rizzo. Vinculação dos árbitros aos precedentes judiciais. Disponível in: < https://www.conjur.com.br/2017-out-03/guilherme-amaral-vinculacao-arbitros-aosprecedentes-judiciais $>$. Acesso em: 20 jul. 2018.

BERALDO, Leonardo de Faria. Curso de Arbitragem: nos termos da Lei no 9.307/96. São Paulo: Atlas, 2014.

BERNARDES, Flávio. Couto. COSTA GONTIJO, Pedro. Augusto. A eficácia vinculante dos precedentes sobre o processo administrativo tributário. In: Rodrigo Araújo Ribeiro; Tiago Flecha de Almeida; Marcelo Andrade Féres; Jason Soares de Albergaria Neto; Alberto Guimarães Andrade; Luiz Gustavo Levate. (Org.). ADVOCACIA PÚBLICA EM JUÍZO. 1ed.Belo Horizonte: D'Plácido, 2018, v. , p. 13-799.

BIANCHI, Bruno Guimarães. Arbitragem no novo código de processo civil: aspectos práticos. Revista de Processo, São Paulo, v.41, n.255 , p. 413-432, maio 2016.

BRASIL. Constituição (1988). Constituição da República Federativa do Brasil.

Disponível in: < http://www.planalto.gov.br/ccivil_03/constituicao/constituicao.htm>. Acesso em: 15 jul. 2018.

BRASIL. LEI N ${ }^{\circ}$ 9.307, de 23 de setembro de 1996. Dispõe sobre a arbitragem. Disponível in: < http://www.planalto.gov.br/ccivil_03/Leis/L9307.htm>. Acesso em: 15 jul. 2018.

BRASIL. Lei No 13.105, de 16 de março de 2015. Código de Processo Civil. Disponível in: < http://www.planalto.gov.br/ccivil_03/_ato2015-2018/2015/lei/113105.htm>. Acesso em: 15 jul. 2018.

BRASIL. Supremo Tribunal Federal. Sentença Estrangeira no 5206 Agravo Regimental. Requerente: MBV Commercial and Export Management Establishment. Requerido: Resil 
Industria e Comercio Ltda. Relator(a): Min. Sepúlveda Pertence, Tribunal Pleno, julgado em 12/12/2001, dj 30 abr. 2004 pp-00029 ement. Vol.-02149-06 pp-00958.

CARMONA, Carlos Alberto. Arbitragem e processo: um comentário à Lei no 9.307/96. 3. ed. ver. atual. e ampl. - São Paulo: Atlas, 2009.

CARMONA, Carlos Alberto. O Processo Arbitral. Revista dos Tribunais online. Disponível in: <

https://edisciplinas.usp.br/pluginfile.php/1963885/mod_resource/content/1/Artigo\%20CAC\% 20-\%200\%20Processo\%20Arbitral.pdf>. Acesso em: 15 jul. 2018.

CINTRA, Antônio Carlos de Araújo; GRINOVER, Ada Pellegrini; DINAMARCO, Cândido Rangel. Teoria geral do processo. 22. ed. rev. e atual., de acordo com a EC 45, de 8.12.2004 e com a Lei 11.232, de 22.12.2005. São Paulo: Malheiros, 2006.

CREMASCO, Suzana Santi; SILVA, Tiago Eler. O caráter jurisdicional da arbitragem o precedente arbitral. Disponível in: <

https://www.direito.ufmg.br/revista/index.php/revista/article/view/159/147>. Acesso em: 20 jul. 2018.

DIDIER Jr. Fredie; BRAGA, Paula Sarno; OLIVEIRA, Rafael Alexandria de. Curso de direito processual civil: teoria da prova, direito probatório, ações probatórias, decisões, precedente, coisa julgada e antecipação dos efeitos da tutela. 11 ed. - Salvador: Ed. Jus Podivm, 2016.

FORBES, Carlos Suplicy de Figueiredo; KOBAYASHI, Patrícia Shiguemi Carta arbitral: instrumento de cooperação jurisdicional. In CARMONA, Carlos Alberto; LEMES, Selma Ferreira; Martins, Pedro Batista (Coord.). 20 anos da lei de arbitragem: homenagem a Petrônio R. Muniz . 1. ed. - São Paulo: Atlas, 2017.

KELSEN, Hans. Teoria Pura do Direito. $8^{\text {a }}$ ed. - São Paulo: Editora WMF Martins Fontes, 2009.

LEAL, Rosemiro Pereira. Teoria Gral do processo: primeiros estudos. $-10^{\circ}$. ed. - Rio de Janeiro: Forense, 2011.

MARTINS, Pedro A. Batista. A arbitragem no Brasil. Revista Síntese de Direito Civil e Processual Civil, São Paulo, v.11, n.68, p. 21-30, nov./dez. 2010.

OLIVEIRA, Júlio Aguiar de. A deliberação como condição de aplicação da proporcionalidade. Revista Brasileira de Direito, 12 (2): p. 143-153, jul. dez. 2016.

PERILLI, Paulo Roberto Godoy. A introdução dos precedentes no Novo Código de Processo Civil. In CASTRO, João Antônio de Lima (Org.). Direito Processual e o novo Código de Processo Civil. Belo Horizonte: Puc Minas, Instituto de Educação Continuada, 2016. 
RIBEIRO, O sistema commom law e a influência dos precedentes judiciais no direito brasileiro. In CASTRO, João Antônio de Lima (Org.). Direito Processual e o novo Código de Processo Civil. Belo Horizonte: Puc Minas, Instituto de Educação Continuada, 2016.

ROCHA, Islane Archanjo. Breve análise sobre os precedentes judiciais na ótica do novo Código de Processo Civil. In CASTRO, João Antônio de Lima (Org.). Direito Processual e o novo Código de Processo Civil. Belo Horizonte: Puc Minas, Instituto de Educação Continuada, 2016.

ROCHA, Pedro Cavalcanti. Apontamentos sobre as principais alterações no instituto da arbitragem no código de processo civil de 2015 (Lei 13.105/2015). Revista de Arbitragem e Mediação, São Paulo, v.13, n.49 , p. 201-223, abr. 2016.

ROQUE, André Vasconcelos; Gajardoni, Fernando da Fonseca. A sentença arbitral deve seguir o precedente judicial do novo CPC? Precedente vinculante não pode ser a causa da arbitragem no Brasil. Disponível in: < https://www.jota.info/opiniao-eanalise/colunas/novo-cpc/sentenca-arbitral-deve-seguir-o-precedente-judicial-novo-cpc07112016>. Acesso em: 20 jul. 2018.

STRAUBE, Frederico José. A vinculação das partes e árbitros ao regulamento de arbitragem. In CARMONA, Carlos Alberto; LEMES, Selma Ferreira; Martins, Pedro Batista (Coord.). 20 anos da lei de arbitragem: homenagem a Petrônio R. Muniz . 1. ed. - São Paulo: Atlas, 2017.

SZKLAROWSKY, Leon Fredja. A arbitragem e sua evolução. Consulex: revista jurídica, Brasília, v.8 n.174,p.38-39, abr,2004.

THEODORO JÚNIOR, Humberto. Novo Código de Processo Civil anotado. 20. ed. rev. e atual. Rio de Janeiro, RJ: Forense, 2016.

TUCCI, José Rogério Cruz e. O árbitro e a observância do precedente arbitral. Disponível in: < https://www.conjur.com.br/2016-nov-01/paradoxo-corte-arbitro-observancia-precedentejudicial>. Acesso em: 20 jul. 2018.

VIANA, Antônio Aurélio de Souza. Precedentes no CPC 2015 e a mutação no ônus argumentativo. 2016320 f. Dissertação (Mestrado) - Pontifícia Universidade Católica de Minas Gerais, Programa de Pós-Graduação em Direito.

WALD, Arnoldo. A evolução do direito e da arbitragem. In LEMES, Selma Ferreira; CARMONA, Carlos Alberto; MARTINS, Pedro Batista (Coord.). Arbitragem : estudos em homenagem ao Prof. Guido Fernando Silva Soares - $2^{\mathrm{a}}$ ed. - São Paulo: Atlas, 2007. Cap. 26. p. 454-463. 